\title{
ANÁlise de Conteúdo SobRe AS DEFinições de CoMpetênCiA, Competência Digital e Competência Digital Docente ${ }^{1}$
}

\author{
Content Analysis on the definitions of Competence, Digital Competence, and \\ Digital Teaching Competence \\ PAZ, Daiane Padula ${ }^{2}$ \\ PONTAROLO, Edilson ${ }^{3}$ \\ SANTOS, Gilson Ditzel ${ }^{4}$ \\ BERNARTT, Maria de Lourdes ${ }^{5}$
}

\begin{abstract}
Resumo
Existe um evidente imbróglio terminológico e conceitual acerca dos termos competência, competência digital e competência digital docente na literatura acadêmica e documental. Visando colaborar com esclarecimentos pontuais, este artigo tem por objetivos: i) identificar definições de competência, competência digital e competência digital docente, no campo da educação, presentes em publicações de relevância acadêmica internacional; ii) analisar de forma quantitativa as contribuições sobre estes temas em um corpus selecionado de referências da área; iii) elaborar definições próprias sobre competência, competência digital e competência digital docente sob um ponto de vista educacional. A metodologia aplicada foi a Análise de Conteúdo, em um corpus de treze referências oriundas de buscas nas bases de dados Web of Science e Scopus, cujos procedimentos analíticos foram realizados com o auxílio do software Atlas.ti. Os dados revelaram que neste conjunto de referências há poucas definições explícitas destes termos e que, quando existem, há nuances nos entendimentos; contudo, percebeuse que, mesmo em distintas formas de expressar tais conceitos, há elementos convergentes no entendimento dos autores, compostos por termos como habilidades, uso e literacia. Por fim, à luz do referencial selecionado, foi possível elaborar definições próprias que emergiram a partir deste estudo e que podem servir para referência e discussão de outros pesquisadores da área.
\end{abstract}

Palavras-chave: Competência. Competência Digital. Competência Digital Docente.

\section{Abstract}

There is an evident terminological and conceptual imbroglio about the terms competence, digital competence and digital teaching competence in academic and documentary literature. To collaborate with specific clarifications, this article aims to: i) to identify definitions of competence, digital competence, and teaching digital competence in the field of education present in publications of international academic relevance; ii) to analyze quantitatively the contributions of these themes in a selected corpus of references of the area; iii) to elaborate proper definitions on competence, digital competence, and teaching digital competence under an educational point of view. The methodology applied was Content Analysis in a corpus of thirteen references from searches in the Web of Science and Scopus databases, whose analytical procedures had been assisted by Atlas.ti software. The data had disclosed that in this set of references there are few explicit definitions of these terms and that, when they exist, there are

\footnotetext{
${ }^{1}$ Este trabalho é inédito e não contou com financiamento para sua realização.

2 Doutoranda do Programa de Pós-graduação em Desenvolvimento Regional da Universidade Tecnológica Federal do Paraná, Campus Pato Branco, da linha de pesquisa Educação e Desenvolvimento. Professora do Colegiado de Letras do Instituto Federal do Paraná, Campus Palmas. E-mail: daiane.paz@ifpr.edu.br.

${ }^{3}$ Doutor em Informática na Educação pela Universidade Federal do Rio Grande do Sul. Professor do Departamento Acadêmico de Informática e do Programa de Pós-Graduação em Desenvolvimento Regional, na linha de pesquisa Educação e Desenvolvimento da Universidade Tecnológica Federal do Paraná, Campus Pato Branco. E-mail: epontarolo@utfpr.edu.br.

${ }^{4}$ Doutor em Administração pela Universidade de São Paulo. Professor dos Programas de Pós-Graduação em Desenvolvimento Regional, Engenharia de Produção e Sistemas da Universidade Tecnológica Federal do Paraná, Campus Pato Branco. E-mail: ditzel@utfpr.edu.br.

${ }^{5}$ Doutora em Educação pela Universidade Estadual de Campinas. Professora do Programa de Pós-graduação em Desenvolvimento Regional da Universidade Tecnológica Federal do Paraná. Líder do Grupo de Pesquisa Políticas Públicas, Educação e Direitos Humanos (GPPEDH), Editora Associada da Revista DRd/UNC. E-mail: marial@uttpr.edu.br.
} 
nuances in the understandings; however, it was noticed that, even in different ways of expressing such concepts, there are converging elements in the understanding of the authors, composed of terms such as abilities, usage, and literacy. Finally, considering the selected referential it was possible to elaborate on proper definitions that had emerged from this study and that can be used for reference and discussion by other researchers in the area.

Keywords: Competence. Digital Competence. Digital Teaching Competence.

\section{INTRODUÇÃO}

Com a popularização da Internet e com o desenvolvimento e expansão das Tecnologias Digitais de Informação e Comunicação (TDIC), muitos setores da sociedade vêm se modificando, tais como saúde, educação, segurança, economia, entre outros. Estas modificações são tão profundas que requerem dos usuários destas tecnologias um rol de competências, denominadas competências digitais, as quais tem sido tratada como essenciais para o exercício da cidadania.

A partir do documento elaborado pelo Parlamento Europeu e Conselho da União Europeia, em 2006, chamado "Recomendações sobre as Competências Essenciais para Aprendizagem ao longo da vida", o termo competência digital tem servido de base para modificações curriculares em instituições escolares europeias e de outros continentes. Contudo, este termo apresenta uma penumbra semântica, evidente em uma variedade de referências, gerando algumas definições semelhantes, outras distintas e muitas, redundantes (SILVA, 2018). Na realidade, este imbróglio terminológico, que implica no conceitual, inicia-se com o vocábulo "competência", o qual provém da área de gestão e administração e que foi levado a outras áreas, como Psicologia, Sociologia, Linguística, Ciências do Trabalho e Educação (MATTOS, 2019; SÁ; PAIXÃO, 2013), gerando diversas e até divergentes acepções. $O$ mesmo ocorre com o termo competência digital docente, que parece não ter uma definição precisa na literatura, 0 que dificulta a orientação para elaboração de referenciais na área educacional bem como políticas públicas que atendam este tema.

Ante tal problemática, questiona-se: Como estão definidos os termos competência, competência digital e competência digital docente na literatura acadêmica? Há paridade entre estas definições nos artigos publicados em periódicos? Existem relações entre as definições e outros dados, como tipo de estudo, país de origem ou idioma de publicação? Há outros termos relacionados emergentes na literatura? Estes questionamentos conduzem aos objetivos deste estudo, que são: i) Identificar definições de Competência (COMP), Competência Digital (CD) e Competência Digital Docente (CDD), em publicações de relevância acadêmica no campo da educação; ii) Analisar de forma qualitativa e quantitativa as contribuições sobre estes temas em um corpus selecionado de referências da área; iii) Elaborar definições próprias sobre COMP, CD e CDD sob um ponto de vista educacional.

O percurso metodológico realizado foi o método de Análise de Conteúdo (AC), de Laurence Bardin (2016), cujo corpus foi composto por treze referências, selecionadas a partir de uma revisão de literatura efetuada previamente pelos pesquisadores nas bases de dados Web of Science e Scopus. Nas três etapas de AC -pré-análise, exploração do material; tratamento dos resultados, inferência e interpretação- utilizou-se o Atlas.ti, um software que possui uma gama de recursos para a análise de dados qualitativos (SILVA JUNIOR; LEÂO, 2018). 
Este estudo não tem por intenção aprofundar-se em nuances terminológicas utilizadas na literatura ou mesmo fazer associações teórico-conceituais que estejam inseridas no bojo das escolhas dos autores das referências analisadas, deseja somente elucidar definições que abrangem campos das competências, do meio digital e da educação, e que fazem parte de pesquisas da atualidade, fato que justifica esta pesquisa.

O presente artigo está organizado em quatro seções, sendo esta primeira a introdução; a segunda, a metodologia adotada, a qual subdivide-se em três subseções, conforme indica o método de Análise de Conteúdo; a terceira, a discussão dos resultados e, por fim, as considerações finais.

\section{METODOLOGIA}

Ciente de que uma boa pesquisa precisa seguir certo rigor e coerência em todas as suas etapas, optou-se pelo método de Análise de Conteúdo (AC), definido como um "conjunto de técnicas de análise das comunicações visando obter por procedimentos sistemáticos e objetivos de descrição do conteúdo das mensagens, indicadores que permitam a inferência de conhecimentos" (BARDIN, 2016, p. 54). Embora seja categorizado como uma abordagem qualitativa, a $\mathrm{AC}$ favorece e, inclusive, prescreve análises de ordem quantitativa, tais como índices de frequências, análise lexicométrica e de coocorrência, em uma tendência que a conduz, em determinados casos, a um método misto, sendo neste estudo, do tipo QUAL+QUAN, no intuito de incorporar pontos fortes de ambas as metodologias (JOHNSON; ONWUEGBUZIE, 2004).

Nos últimos anos tem sido desenvolvidos diversos softwares para Análise de Dados Qualitativos Assistida por Computador, chamados CAQDAS (YIN, 2016), os quais facilitam o trabalho de pesquisadores, sobretudo quando há necessidade de várias análises sucessivas ou quando implica em operações estatísticas (BARDIN, 2016). Nesta pesquisa foi utilizado o software Atlas.ti, versão 9.1, devido suas funcionalidades, como destaque de citações, aplicação de códigos, análise de redes, e por mostrar-se adequado para estudos que envolvem a AC (SILVA JUNIOR; LEÃO, 2018).

De maneira geral, o método AC se organiza em três etapas sendo a primeira, a préanálise; a segunda, a exploração do material; e a terceira, o tratamento dos resultados, inferência e interpretação, cujos procedimentos estão descritos de forma detalhada nas próximas seções.

\subsection{Pré-análise}

A pré-análise inicia pela leitura flutuante. Esta primeira fase do método de $A C$ tem por missões a seleção dos documentos (corpus), a formulação de hipóteses e objetivos, e a elaboração de indicadores que fundamentarão as interpretações realizadas (BARDIN, 2016). Tais missões, não possuem uma sequência estipulada, entretanto, compõem uma tríade totalmente articulada, pois uma exerce importante influência sobre a outra.

Bardin (2016, p.126) define corpus como "conjunto de documentos tidos em conta para serem submetidos aos procedimentos analíticos". Nesta pesquisa, o corpus advém de um procedimento de revisão de literatura, realizado previamente pelos pesquisadores nas bases de dados Scopus e Web of Science, através da sentença: (("digital competenc" OR "digital skill" OR "digital literac*")) AND (("teach" OR "educat" OR "professor")), que resultou em um portfólio bibliográfico com 47 referências que foram 
divididas em categorias. A categoria de interesse desta pesquisa é a primeira, denominada Definição, a qual contém treze estudos que tratam ou mapeiam os termos e conceitos relacionados à competência digital, de relevância internacional, conforme demonstra o Quadro 1.

Após a seleção do corpus, Bardin (2016) sugere que seja feita a referenciação, que consiste na definição dos índices e indicadores. No caso de textos escritos, os índices podem ser palavras, frases ou termos destacados, enquanto os indicadores, as regras de enumeração escolhida pelo pesquisador como critério de sua magnitude, podendo ser, por exemplo, a frequência de ocorrência.

Quadro 1- Referências selecionadas para análise

\begin{tabular}{|c|c|c|c|}
\hline TITULO & AUTORES & REVISTA & ANO \\
\hline $\begin{array}{l}\text { Media Education, Media Literacy and } \\
\text { Digital Competence }\end{array}$ & $\begin{array}{l}\text { Gutierrez Martin, Alfonso; } \\
\text { Tyner, Kathleen }\end{array}$ & Comunicar & 2012 \\
\hline $\begin{array}{l}\text { De la competencia digital y audiovisual a } \\
\text { la competencia mediática: dimensiones e } \\
\text { indicadores }\end{array}$ & $\begin{array}{l}\text { Pérez, María Amor; } \\
\text { Delgado, Águeda }\end{array}$ & Comunicar & 2012 \\
\hline Taxonomy of literacies & Stordy, Peter Howard & Journal of Documentation & 2015 \\
\hline $\begin{array}{l}\text { On the issues of digital competence in } \\
\text { educational contexts }-a \text { review of } \\
\text { literature }\end{array}$ & Pettersson, Fanny & $\begin{array}{l}\text { Education and Information } \\
\text { Technologies }\end{array}$ & 2018 \\
\hline $\begin{array}{l}\text { Competencia digital: una necesidad del } \\
\text { profesorado universitanio en el siglo XXXI }\end{array}$ & $\begin{array}{l}\text { Espinosa, M. Paz Prendes; } \\
\text { Porlán, Isabel Gutiérrez; } \\
\text { Sánchez, Francisco Martínez }\end{array}$ & $\begin{array}{l}\text { Revista de Educación a } \\
\text { Distancia }\end{array}$ & 2018 \\
\hline $\begin{array}{l}\text { Digital competence and digital literacy in } \\
\text { higher education research: Systematic } \\
\text { review of concept use }\end{array}$ & $\begin{array}{l}\text { Spante, Maria; } \\
\text { Hashemi, Sylvana Sofkova; } \\
\text { Lundin, Mona; } \\
\text { Algers, Anne; } \\
\text { Wang, Shuyan }\end{array}$ & Cogent Education & 2018 \\
\hline $\begin{array}{l}\text { Comprendiendo los aspectos cuiturales y } \\
\text { sociales de las competencias digitales } \\
\text { docentes }\end{array}$ & Engen, Bard Ketil & Comunicar & 2019 \\
\hline $\begin{array}{l}\text { Impacto de la productividad científica } \\
\text { sobre competencia digital de los futuros } \\
\text { docentes: Aproximación bibliométrica en } \\
\text { Scopus y Web of Science }\end{array}$ & $\begin{array}{l}\text { García, A.M. Rodríguez; } \\
\text { Torres, Juan Manuel Trujillo; } \\
\text { Rodríguez, José Sánchez }\end{array}$ & $\begin{array}{l}\text { Revista Complutense de } \\
\text { Educación }\end{array}$ & 2019 \\
\hline $\begin{array}{l}\text { Competencias docentes } \\
\text { transformaciones en la educación en la } \\
\text { era digital }\end{array}$ & $\begin{array}{l}\text { Villa, Sandra Villarreal; } \\
\text { Guliany, Jesús García; } \\
\text { Palma, Hugo Hernández; } \\
\text { Sanabria, Ernesto Steffens } \\
\end{array}$ & Formación Universitaria & 2019 \\
\hline $\begin{array}{l}\text { Competencias digitales docentes: un } \\
\text { acercamiento inicial }\end{array}$ & $\begin{array}{l}\text { Granados, Alejandra Castro; } \\
\text { Diaz, Karla Yanitzia. A. }\end{array}$ & $\begin{array}{l}\text { Revista Electrónica Calidad } \\
\text { en la Educación Superior }\end{array}$ & 2020 \\
\hline $\begin{array}{l}\text { From digital literacy to digital } \\
\text { competence: the teacher } \\
\text { competency (TDC) framework }\end{array}$ & Falloon, Garry & $\begin{array}{lr}\text { Educational } & \text { Technology } \\
\text { Research } & \text { and } \\
\text { Development } & \\
\end{array}$ & 2020 \\
\hline $\begin{array}{l}\text { A Scientometric Study of Digital Literacy, } \\
\text { ICT Literacy, Information Literacy, and } \\
\text { Media Literacy }\end{array}$ & $\begin{array}{l}\text { Park, Hyejin; } \\
\text { Kim, Han Sung; } \\
\text { Park, Han Woo }\end{array}$ & $\begin{array}{l}\text { Joumal of Data and } \\
\text { Information Science }\end{array}$ & 2020 \\
\hline Digital literacy: A review of literature & \begin{tabular}{|l|} 
Reddy, Pritika; \\
Sharma, Bibhya; \\
Chaudhary, Kaylash \\
\end{tabular} & $\begin{array}{l}\text { International Joumal of } \\
\text { Technoethics }\end{array}$ & 2020 \\
\hline
\end{tabular}

Fonte: Dados da pesquisa.

Através da leitura flutuante pôde-se perceber que existem diversos outros conceitos emergentes na literatura, assim, realizou-se o processo de codificação e categorização delimitando-se os índices em duas categorias, com seus critérios, descritas no Quadro 2. 
Quadro 2- Categorias e índices da análise

\begin{tabular}{|c|c|c|c|}
\hline \multicolumn{2}{|r|}{ CATEGORIA } & İNDICE & DESCRIÇÃO \\
\hline \multirow[t]{3}{*}{1} & \multirow{3}{*}{$\begin{array}{l}\text { DEF_C } \\
\text { (Definições } \\
\text { explicitamente } \\
\text { relacionadas às } \\
\text { Competências) }\end{array}$} & Competência & Definição de Competência(s) relacionada \\
\hline & & Competência Digital & Definição de Competência Digital \\
\hline & & Competência Digital Docente & Definição de Competência Digital Docente \\
\hline \multirow[t]{5}{*}{2} & \multirow{5}{*}{$\begin{array}{l}\text { OUT } \\
\text { (Outras } \\
\text { definições) }\end{array}$} & Literacia/Alfabetização Digital & Definição de Literacia/Alfabetização Digital \\
\hline & & Alfabetização Midiática & Definição de Alfabetização Midiática \\
\hline & & Competência Docente & Definição de Competência Docente \\
\hline & & Competência Digital Profissional & $\begin{array}{l}\text { Definição de Competência Digital } \\
\text { Profissional }\end{array}$ \\
\hline & & Outras definições & Outras definições mencionadas \\
\hline
\end{tabular}

Fonte: Dados da pesquisa.

A categoria 1 (DEF_C), em destaque no quadro 2, foi estabelecida para atingir o objetivo essencial deste estudo, o qual consiste em identificar na literatura os conceitos de Competência (COMP), Competência Digital (CD) e Competência Digital Docente (CDD), o que justifica a definição destes três índices. Embora a definição dos elementos da categoria OUT não seja o foco deste estudo, optou-se por não desprezar as menções surgidas nos textos, pois elas poderão servir tanto para discussões e inferências, em uma recopilação de outros termos e/ou conceitos associados ao universo de competências digitais no âmbito educacional, quanto para outros estudos relacionados. Outros conceitos com menor prevalência foram considerados como "outras definições". Ainda na etapa de pré-análise é preciso realizar a organização do material de forma que facilite seu manuseio. Neste caso, criou-se um projeto no software Atlas.ti e realizou-se a exportação dos treze artigos em formato pdf para, posteriormente, iniciar os procedimentos da segunda etapa da AC.

\subsection{Exploração do material}

A exploração do material é a etapa em que se aplica sistematicamente os procedimentos planejados na pré-análise, revisando-os. Por isso, realizou-se a releitura do corpus, destacando-se, através do recurso citações do Atlas.ti, excertos considerados relevantes, conformando, as unidades de contexto. Em cada unidade, identificou-se os índices (unidades de registro), e aplicou-se os códigos criados no software. Paralelamente, foram sendo criadas anotações no copo dos textos lidos através dos recursos citações e comentários e, ao término de cada leitura, um fichamento individual, através da ferramenta memo. Ainda nesta etapa de exploração, elaborou-se uma matriz para sistematização das informações gerais das referências e de aspectos a serem analisados (Quadro 3).

Segundo Bardin (2016, p.132) a etapa de exploração do corpus é "longa e fastidiosa", sobretudo quando há significativo volume de dados a serem analisados; porém com as funcionalidades disponíveis atualmente nos CAQDAS é possível otimizar o trabalho. Yin (2016) considera que o maior desafio para a análise qualitativa é que não existem fórmulas pré-estabelecidas, assim o pesquisador deverá estipular seus critérios e parâmetros e, ao mesmo tempo, desenvolver os demais procedimentos de análise. Nesse sentido, convém dizer que o êxito da pesquisa dependerá da expertise do pesquisador tanto para aplicar o método AC, quanto para o manejo dos softwares elegidos, se for o caso. 
Quadro 3- Matriz com dados para análise

\begin{tabular}{|l|l|}
\hline Referência & Identificação geral da referência bibliográfica (Autores, título, ano) \\
\hline Ano & Ano de publicação \\
\hline Revista & Revista de publicação \\
\hline País do texto & País mencionado no texto e/ou país das instituições mencionadas. \\
\hline Instituição dos autores & Instituições vinculadas aos autores nos dados da referência \\
\hline Idioma & Idioma de publicação \\
\hline Tipo de estudo & $\begin{array}{l}\text { Análise documental; Discussão; Estudo de caso; Revisão de } \\
\text { literatura }\end{array}$ \\
\hline Nível de abrangência & $\begin{array}{l}\text { Micro- Estudo com perspectiva local (curso, instituição, cidade) } \\
\text { Meso- Estudo com perspectiva regional (região/ país) } \\
\text { Macro- Estudo com perspectiva global (global/global) }\end{array}$ \\
\hline $\begin{array}{l}\text { Termos } \\
\text { prevalecentes/emergentes }\end{array}$ & $\begin{array}{l}\text { Termos relacionados à Competência/Competência Digital e/ou } \\
\text { Competência Digital Docente que tenham relevância no texto. }\end{array}$ \\
\hline Definição de Competência & $\begin{array}{l}\text { (1) Não mencionado- Não consta nenhuma menção sobre o tema; } \\
\text { (2) Mencionado, mas não definido- Há menção, mas nenhuma } \\
\text { definição explícita; } \\
\text { (3) Definido pelos autores- Há, no mínimo, uma definição } \\
\text { elaborada pelos autores; } \\
\text { (4) Definido por citação de outros autores- As definições } \\
\text { existentes são citações diretas ou indiretas de outros autores; } \\
\text { (5) Definido pelo autor e por citações de outros autores- } \\
\text { Constam ambos os tipos de definições. }\end{array}$ \\
\hline $\begin{array}{l}\text { Definição de Competência Digitalo Competência Digital } \\
\text { Docente }\end{array}$
\end{tabular}

Fonte: Dados da pesquisa.

Finalizando esta segunda etapa, realizou-se o preenchimento de todas as informações na matriz para análise no software Microsoft Excel e, também a emissão de um relatório com todas as referenciações feitas, no Atlas.ti.

\subsection{Tratamento dos resultados, inferência e interpretação}

A última etapa do método de $\mathrm{AC}$ consiste no tratamento de resultados brutos para que sejam significativos e válidos, ou seja, que permitam a proposição de inferências e interpretação acorde aos objetivos previstos (BARDIN, 2016). Neste estudo os dados foram coletados no Atlas.ti, compilados em planilhas para elaboração de gráficos e, em alguns casos, tratados no software Tableau, versão 2020.1. Essa exploração de dados permitiu ampliar análises e interpretações, as quais se deram em três perspectivas: i) macrodados; ii) definições; iii) concepções, detalhadas na sequência.

i) Macrodados: Embora a análise de aspectos do tipo bibliométrico não faça parte dos objetivos desta pesquisa, não se pode ignorar o contexto de origem dos estudos; isso porque, ao tratar de conceitos, expressos em linguagem escrita, infere-se que podem estar carregados de aspectos culturais, locais e sociais plasmados tanto no idioma quanto no meio em que circulam. Nesta perspectiva, realizou-se um cruzamento das seguintes variáveis: referência, revista de publicação, país de origem do estudo, idioma de publicação, tipo de estudo e nível de abrangência (Figura 1). 
Figura 1- Análise das variáveis referência, revista de publicação, país de origem do estudo, idioma de publicação, tipo de estudo e nível de abrangência

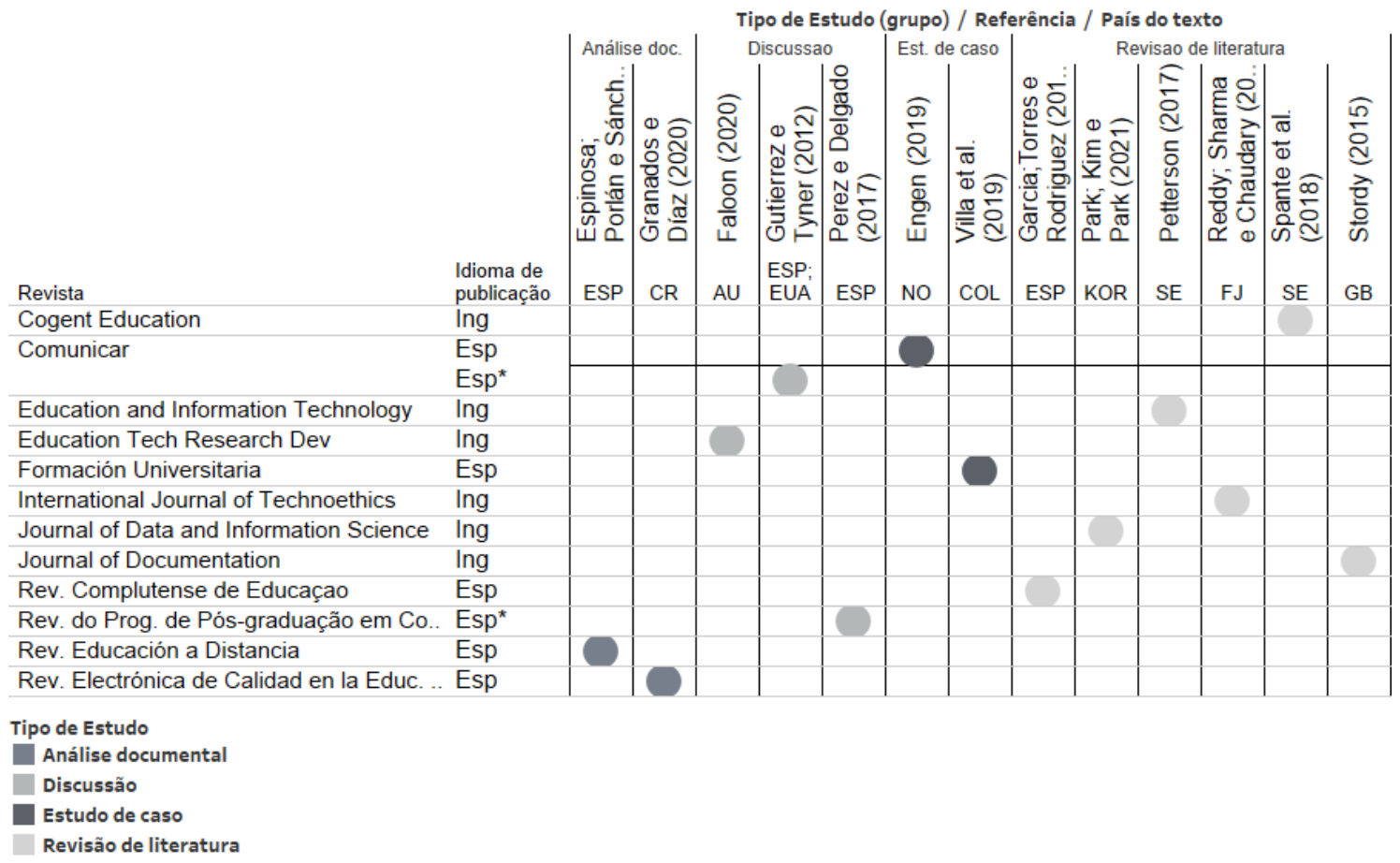

Fonte: Dados da pesquisa.

Os dados demonstram que há relação entre o tipo de estudo, nível de abrangência e idioma, uma vez que os estudos de caso e discussão são no nível micro e meso, ou seja, se limitam ao local e regional, enquanto estudos de revisão de literatura, os quais são majoritariamente publicados em inglês, são de maior abrangência, atingindo o nível macro. Como os artigos deste escopo advém de diferentes periódicos, exceto dois que são da mesma revista, não se identificou nenhuma relação entre periódico, tipo de estudo e abrangência. Quanto ao idioma de publicação, há paridade, uma vez que seis referências estão em inglês e sete, em espanhol. Há duas em versão bilíngue, identificadas com um * na Fig. 1. Quanto ao ano de publicação, as referências são consideradas recentes, distribuídas da seguinte forma: 2012 (2), 2015 (1), 2018 (3), 2019 (3), 2020 (3), 2021 (1).

Os estudos demonstraram que o tema competência digital tem sido de interesse de organismos europeus, especialmente porque neste continente se originaram documentos de importância internacional como o Conselho da União Europeia (2006), Organização para a Cooperação e o Desenvolvimento Econômico (2019), Organização das Nações Unidas para Educação, Ciência e Cultura (2019), entre outros. Neste escopo, há um total de sete estudos advindos de universidades europeias (um deles integrado com universidade estado-unidense), sendo quatro de instituições espanholas, país que concentra mais publicações sobre o tema.

ii) Definições: O levantamento de citações e aplicação de códigos realizados na etapa de pré-análise no Atlas.ti, resultou em dados quantitativos sobre as definições de COMP, CD e CDD no corpus analisado. Ao gerar a relação tabela-código, obteve-se os seguintes dados (Tabela 1): 
Tabela 1- Quantitativos de citações sobre Competência, Competência Digital e Competência Digital Docente

\begin{tabular}{|c|c|c|c|c|c|c|c|c|}
\hline & \multicolumn{2}{|c|}{ DEF1: Competência } & \multicolumn{2}{|c|}{ DEF2: CD } & \multicolumn{2}{|c|}{ DEF3: CDD } & \multicolumn{2}{|c|}{ TOTAL } \\
\hline Referência & Citações & Percentual & Citaçôes & Percentual & Citações & Percentual & Citações & Aporte total \\
\hline Granados e Díaz (2020) & 15 & $11,6 \%$ & 6 & $4,7 \%$ & 3 & $2,3 \%$ & 24 & $18,6 \%$ \\
\hline Engen (2019) & 7 & $5,4 \%$ & 2 & $1,5 \%$ & 6 & $4,7 \%$ & 15 & $11,6 \%$ \\
\hline Park; kim e Park (2021) & 0 & $0,0 \%$ & 1 & $0,8 \%$ & 0 & $0,0 \%$ & 1 & $0,8 \%$ \\
\hline Perez e Delgado (2017) & 4 & $3,1 \%$ & 4 & $3,1 \%$ & 0 & $0,0 \%$ & 8 & $6,2 \%$ \\
\hline Petterson (2017) & 3 & $2,3 \%$ & 5 & $3,9 \%$ & 4 & $3,1 \%$ & 12 & $9,3 \%$ \\
\hline $\begin{array}{l}\text { Espinosa; Porlán e } \\
\text { Sánchez (2018) }\end{array}$ & 3 & $2,3 \%$ & 4 & $3,1 \%$ & 4 & $3,1 \%$ & 11 & $8,5 \%$ \\
\hline $\begin{array}{l}\text { Reddy; Sharma e } \\
\text { Chaudary }(2020)\end{array}$ & 6 & $4,7 \%$ & 1 & $0,8 \%$ & 0 & $0,0 \%$ & 7 & $5,4 \%$ \\
\hline $\begin{array}{l}\text { Garcia; Torres e } \\
\text { Rodriguez (2019) }\end{array}$ & 1 & $0,8 \%$ & 1 & $0,8 \%$ & 0 & $0,0 \%$ & 2 & $1,5 \%$ \\
\hline Spante et al. (2018) & 1 & $0,8 \%$ & 12 & $9,3 \%$ & 3 & $2,3 \%$ & 16 & $12,4 \%$ \\
\hline Stordy (2015) & 11 & $8,5 \%$ & 0 & $0,0 \%$ & 0 & $0,0 \%$ & 11 & $8,5 \%$ \\
\hline Villa et al. (2019) & 1 & $0,8 \%$ & 1 & $0,8 \%$ & 1 & $0,8 \%$ & 3 & $2,3 \%$ \\
\hline Faloon (2020) & 7 & $5,4 \%$ & 2 & $1,5 \%$ & 2 & $1,5 \%$ & 11 & $8,5 \%$ \\
\hline Gutierrez e Tyner (2012) & 5 & $3,9 \%$ & 3 & $2,3 \%$ & 0 & $0,0 \%$ & 8 & $6,2 \%$ \\
\hline Totais & 64 & $49,6 \%$ & 42 & $32,6 \%$ & 23 & $17,8 \%$ & 129 & $100,0 \%$ \\
\hline
\end{tabular}

Fonte: Dados da pesquisa.

A definição que teve maior número de menções foi a de COMP, representando 49,6\% da análise, enquanto CD e CDD, somente $32,6 \%$ e 17,8\%, respectivamente. Imaginase que esta discrepância se dá porque muitos dos autores utilizam o termo literacia digital, desconsiderado nesta análise por entendê-lo como relacionado, mas não sinônimo de CD. Outro aspecto que pode haver conduzido aos baixos índices de algumas citações, é que nem sempre as definições estão explícitas nos textos. A magnitude das citações feitas pelos autores em cada um dos conceitos está expressa na Figura 2.

Os dados revelam que os autores Granados; Díaz (2020) tiveram significativa contribuição no quantitativo de citações dos termos competência (15) e competência digital (6) e competência digital docente (3 citações). Outros autores tiveram contribuições mais díspares em cada conceito, como por exemplo Stordy (2015), com 11 citações sobre COMP e zero sobre CD e CDD. Infere-se que estas dissonâncias se dão pelos diferentes objetivos das pesquisas. 
Figura 2. Quantitativo de citações sobre os códigos Competência, Competência Digital e Competência Digital Docente

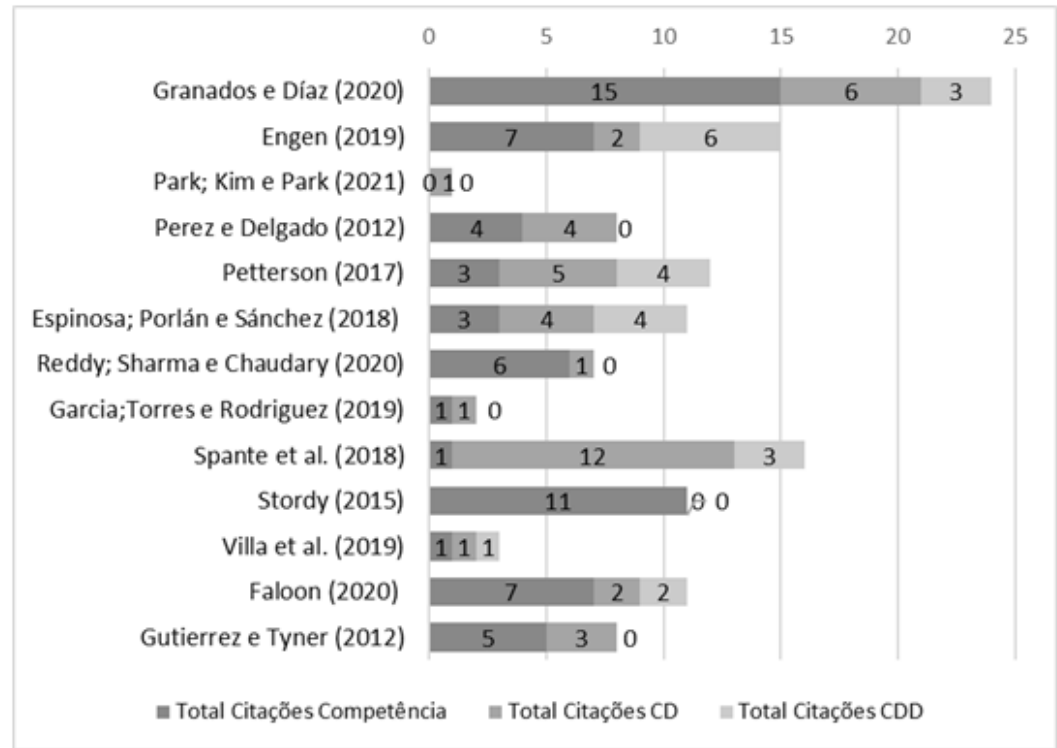

Fonte: Dados da pesquisa.

Para avaliar os valores típicos de uma distribuição, utiliza-se medidas de tendência central (DOANE; SEWARD, 2014). Neste caso, foram identificadas a média, a moda, a mediana e o desvio padrão de cada uma das três séries de dados (total de citações sobre COMP, CD e CDD), conforme demonstra o Quadro 4.

Quadro 4. Medidas de tendência das citações sobre os códigos

\begin{tabular}{|l|l|l|l|l|}
\hline & Média & Mediana & Moda & Desvio padrão \\
\hline COMP & 4,92 & 4,00 & 1,00 & 4,35 \\
\hline CD & 3,23 & 2,00 & 1,00 & 3,19 \\
\hline CDD & 1,77 & 1,00 & 0,00 & 2,05 \\
\hline
\end{tabular}

Fonte: Dados da pesquisa.

A média, que é o ponto de equilíbrio da distribuição dos valores, apresentou bastante diferença entre as três séries, sendo a competência com maior índice. A moda, ou seja, o valor com maior frequência de ocorrência nos dados, foi de 1,00 tanto na COMP quanto na CD, seguido por 0,00 na CDD, o que justifica seu baixo índice de citações, seis dos treze trabalhos não citavam CDD. A mediana entre CD e CDD foi semelhante $(1,00 \mathrm{e}$ $2,00)$, enquanto na COMP foi mais elevada $(4,00)$. Por outro lado, os índices de desvio padrão das três séries demonstram que há significativa dispersão ao redor da média, ou seja, não há uma uniformidade nos dados. Isso pôde ser ratificado através do coeficiente de variância que na série COMP é de 88,4\%, na série CD é de 98,7\% e CDD 115,8\%.

A análise quantitativa das três séries de citações é importante porque permite identificar o quanto cada referência aporta sobre aquele tema. Contudo, considerou-se necessário identificar a natureza das citações levantadas no que se refere à definição dos conceitos em voga. Assim, foram estabelecidos alguns critérios, conforme já demonstrado no Quadro 3, que resultaram em cinco categorias, a saber: não mencionado (NM); mencionado, mas não definido (MND); definido pelo autor (DA); definido por citação de outros autores (DCOA); definido pelo autor e por citações de outros autores (DACOA). Estes critérios foram aplicados no relatório das citações codificadas no Atlas.ti, logo, tabulados e representados graficamente. 
Figura 4. Distribuição dos critérios analisados das citações

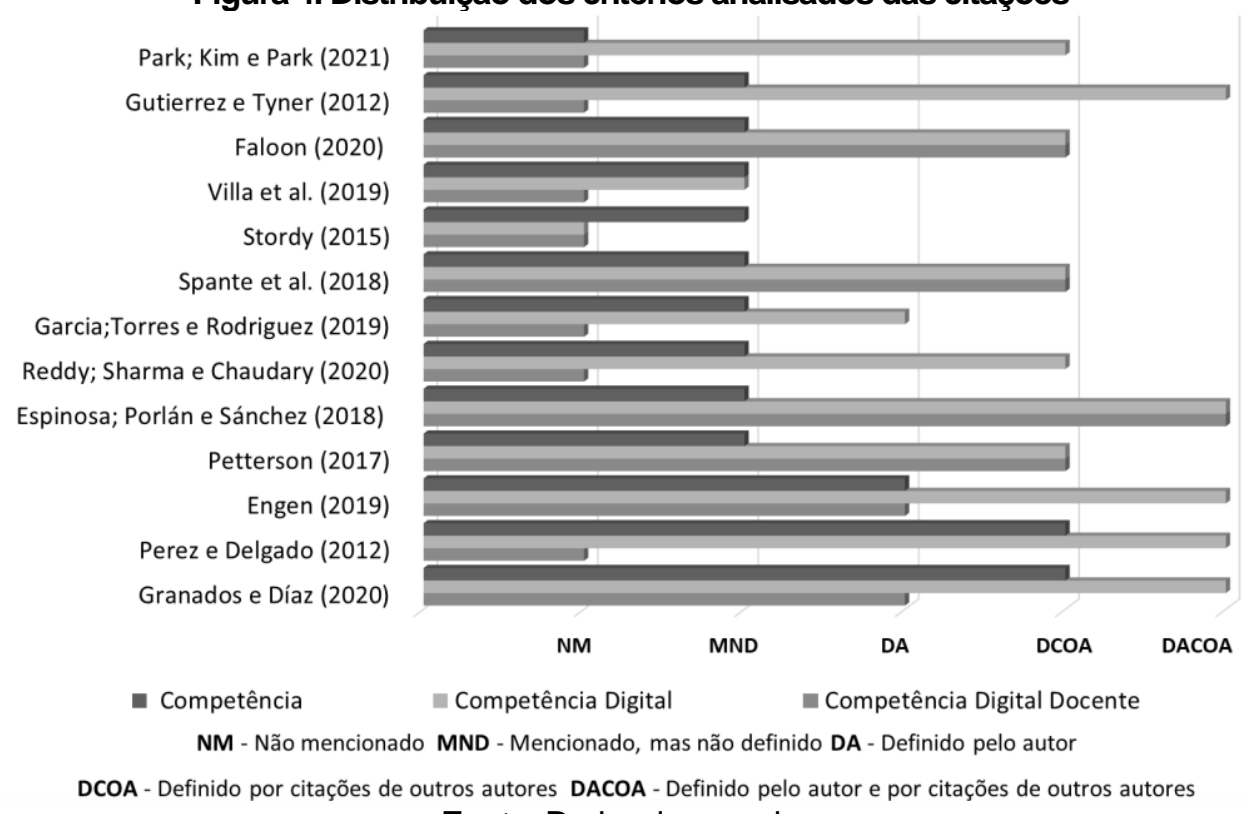

Fonte: Dados da pesquisa.

Os dados na Figura 4 ilustram que a disparidade de aporte das referências não se limita aos dados quantitativos como já demonstrado; esse fenômeno ocorreu também na qualificação dos dados levantados. Percebe-se que, os índices se mantêm majoritariamente no primeiro e segundo critérios (NM e MND), o que significa que a maioria dos autores não apresenta definições para Competência, Competência Digital e/ou Competência Digital Docente. Das 39 possibilidades, somente 17 trouxeram contribuições neste aspecto, sendo quatro definido pelos autores (DA), dez definido por citação de outros autores (DCOA) e, seis definido pelo autor e por citações de outros autores em conjunto (DACOA).

Avaliando-se cada uma das três séries de dados de forma isolada, (COMP, CD e CDD, respectivamente), identifica-se que: i) embora o termo competência tenha apresentado maior número de citações (total de 64, conforme Tabela 1), este termo é pouco definido no corpus analisado, uma vez que somente três referências apresentaram conceitos elaborados, sendo uma definida pelos próprios autores, e outras duas, através de citações de outros autores; ii) o termo competência digital apresenta um cenário totalmente distinto; identificou-se que somente duas referências não apresentaram definição para este termo, enquanto as demais definiram tanto pelos autores (1 ocorrência), por citação de outros autores (5 ocorrências) e das duas formas (5 ocorrências); iii) o termo competência digital docente teve baixo número de citações (23, conforme Tabela 1), com medida central de moda zero, ou seja, a maioria dos autores sequer o citou.

Esta análise permite criar duas hipóteses: a primeira, que o corpus analisado não tinha por objetivo conceituar CDD, mesmo que este seja o tema central dos artigos; a segunda, há uma lacuna na definição deste termo, talvez por sua complexidade, ou por outras escolhas por parte dos autores. Considerando-se esta possibilidade, realizou-se, ainda na etapa de pré-análise, o levantamento de termos prevalecentes/emergentes, ou seja, outros relacionados à COMP, CD e CDD que constam nas referências analisadas (Quadro 5). 
Esta compilação é relevante não só para trazer à tona o rol de expressões utilizadas na literatura internacional (por isso foram considerados os termos no idioma original), mas também para justificar a ausência de menções dos termos COMP, CD ou CDD em algumas das referências analisadas. Observa-se, por exemplo que PARK; KIM; PARK, (2020) não mencionaram COMP nem CDD, porque seu enfoque estava na CD. Fenômeno semelhante ocorre com Stordy (2015) que não menciona CD nem CDD porque seu artigo trata de diversas literacias, e sua escolha conceitual se direciona à literacia digital.

Quadro 5. Termos relacionados no corpus analisado

\begin{tabular}{|c|c|c|}
\hline Referência & Idioma & Termos Prevalecentes/Emergentes \\
\hline Granados e Díaz (2020) & Espanhol & Competencia digital docente: Competencias del Siglo XXI \\
\hline Engen (2019) & Espanhol & $\begin{array}{l}\text { Docente profesional digitalmente competente; } \\
\text { Competencia digital profesional; Competencias de traducción } \\
\text { y conversión de la tecnología }\end{array}$ \\
\hline Park; Kim e Park (2021) & Inglês & Digital Competence; Digital Literacy \\
\hline Perez e Delgado (2012) & Espanhol $^{*}$ & $\begin{array}{l}\text { Competencia Digital; Competencia Audiovisual; } \\
\text { Competência Mediática; Alfabetización mediática }\end{array}$ \\
\hline Petterson (2017) & Inglês & Digital Competence \\
\hline $\begin{array}{l}\text { Espinosa; Porlán e Sánchez } \\
\text { (2018) }\end{array}$ & Espanhol & $\begin{array}{l}\text { Competencia profesional; Competencia profesional docente; } \\
\text { Competencia digital docente; Competencia TIC }\end{array}$ \\
\hline $\begin{array}{l}\text { Reddy; Sharma e Chaudary } \\
(2020)\end{array}$ & Inglês & Digital Competence \\
\hline $\begin{array}{l}\text { Garcia; Torres e Rodriguez } \\
(2019)\end{array}$ & Espanhol & Competencia Digital \\
\hline Spante et al. (2018) & Inglês & Digital Competence; Digital Literacy \\
\hline Stordy (2015) & Inglês & $\begin{array}{l}\text { Literacies } \\
\text { Digital Literacy }\end{array}$ \\
\hline Villa et al. (2019) & Espanhol & $\begin{array}{l}\text { Competencia Docente; Competencia Digital; } \\
\text { Competencias estandarizadas en TIC }\end{array}$ \\
\hline Faloon (2020) & & $\begin{array}{l}\text { Digital Competence; Teacher digital competence; Performative } \\
\text { competence; Technical competence; Teaching specific } \\
\text { competence; } \\
\text { Personal-professional competencies }\end{array}$ \\
\hline Gutierrez e Tyner (2012) & Espanhol $^{*}$ & Competencia digital; Competencia social y ciudadana \\
\hline
\end{tabular}

Fonte: Dados da pesquisa.

Segundo Gutiérrez e Tyner (2012, p.36), a CD "viene a unir se al maremágnum terminológico", e consideram que o termo se aproxima mais de digital literacy, em inglês, do que alfabetización digital, tradução corrente ao espanhol. Na língua portuguesa, a dubiedade se dá pela preferência do termo alfabetização ou letramento, no Brasil, e por literacia, em Portugal (SILVA; BEHAR, 2019). Krumsvik; Røkenes (2014) destacam que há, na literatura geral, exemplos de uso de mais do que uma terminologia no mesmo texto, de forma sinonímica, o que agudiza, ainda mais, a confusão conceitual. Porém, outros termos surgem na literatura, sendo alguns amplamente conhecidos, como "Computer Literacy, Information Literacy, Media Literacy, Digital Literacy, Digital Fluency" (SILVA; BEHAR, 2019, p.16), e outros nem tanto, como Digital Pedagogy, ICT Competence, e Pedagogical Digital Competence (PETTERSSON, 2017). Entre os mais usados e de maneira indistinta, estão literacia digital e competência digital (LUCAS; MOREIRA; COSTA, 2017). Esta pesquisa não se adentrará nas diferenças terminológicas e seus desdobramentos exotópicos porque não faz parte dos objetivos traçados, porém destaca aqui, a dimensão desta ambiguidade terminológica e conceitual.

iii) Concepções: Uma das vantagens da abordagem qualitativa é que ela permite não só a revisão, mas também a elaboração de novos conceitos e categorias; isso ocorre a partir do entendimento de correlações entre elementos prevalecentes, sendo, neste caso, as citações que expressam a voz dos autores. Entre os objetivos propostos neste estudo, está o de identificar definições de competência, competência digital e competência digital docente no campo da educação, presentes em publicações de relevância acadêmica; procedimento que só é possível devido aos processos realizados nas etapas 
anteriormente descritas. Assim, para identificar e visualizar as concepções emergentes no corpus analisado, realizou-se o procedimento de rede semântica no Atlas.ti a partir dos três códigos do grupo DEF e realizou-se o levantamento de quais autores apresentaram definições (próprias ou por citações) sobre COMP, CD e CDD (Quadro 6).

Quadro 6- Distribuição das definições apresentadas pelos autore
\begin{tabular}{|l|l|l|l|}
\hline Referência & COMP & CD & CDD \\
\hline Granados e Díaz (2020) & & & \\
\hline Engen (2019) & & & \\
\hline Park; Kim e Park (2021) & & & \\
\hline Perez e Delgado (2012) & & & \\
\hline Petterson (2017) & & & \\
\hline Espinosa; Porlán e Sánchez (2018) & & & \\
\hline Reddy; Sharma e Chaudary (2020) & & & \\
\hline Garcia; Torres e Rodriguez (2019) & & & \\
\hline Spante et al. (2018) & & & \\
\hline Stordy (2015) & & & \\
\hline Villa et al. (2019) & & & \\
\hline Faloon (2020) & & & \\
\hline Gutierrez e Tyner (2012) & & \\
\hline
\end{tabular}

Fonte: Dados da pesquisa.

Após todos os procedimentos de identificação, referenciação e categorização e análise minuciosa de diversos aspectos que convergem aos temas centrais deste estudo, importa, neste ponto, trazer à tona as definições levantadas em cada referência, procedimento que Bardin (2016) chama de função analítica. Como já mencionado, este estudo não pretende fazer nenhum tipo de análise de teor linguístico ou discursivo, tampouco exegese sobre o tema, objetiva, tão somente, identificar as definições para COMP, CD e CDD presentes no corpus analisado através do levantamento das informações contida nas mensagens, cuja síntese destaca-se a seguir.

Competência: Granados e Díaz (2020) entendem que sua definição foi se fortalecendo com o passar do tempo, com aportações de diversos autores, entre os quais destacam o compêndio feito por Zavala; Muñoz; Lozano, (2017) onde consta: "la capacidad del ser humano para realizar un conjunto de actuaciones, mediante la articulación de sus múltiples recursos personales [...]con el propósito de lograr una respuesta satisfactoria a un problema planteado en un contexto determinado" (Rangel, 2015, p. 334, apud Granados; Díaz, 2020, p. 65). Agregam ainda que, além do entendimento de uma atuação integral que aciona saberes, as competências são uma capacidade do indivíduo essencial para sua participação cidadã ativa, e que "muchas de estas se adquieren en el proceso de formación educativa y se complementa en la dinámica cotidiana" (GRANADOS; DÍAZ, 2020, p.66).

Engen (2019, p.12) destaca: “competencia es conocimiento en acción". Ao relacioná-la com as TDIC, este autor considera a necessidade do desenvolvimento de novas competências, as quais serão chave para o novo papel na sociedade do conhecimento. Neste sentido, Pérez e Delgado (2012), afirmam que as competências transcendem a tradição de base behaviorista da aprendizagem, rumo a uma perspectiva de construtivismo social, que inclui conhecimentos e destrezas, bem como habilidades para enfrentar demandas complexas em certos contextos. Assim, as autoras concordam com a concepção de Philip Perrenoud, que define que ser competente é "ser capaz de ativar e utilizar os conhecimentos relevantes para enfrentar determinadas situações e problemas" (Perrenoud, 2004, apud Pérez e Delgado, 2012).

Competência Digital: Granados e Díaz (2020) entendem que a CD não se reduz ao fato de saber utilizar tecnologia, mas significa compreender seu impacto e como integrá- 
la efetivamente na sociedade, sendo, portanto, essencial para a vida adulta e indispensável para os docentes. Destacam o conceito trazido por Marquès (2009) compreendida como: "combinação de conhecimentos, habilidades e capacidades, em conjunção com valores e atitudes, para alcançar objetivos com eficácia e eficiência em contextos e com ferramentas digitais" (Marquès, 2009 apud Granados e Díaz, 2020). Consideram também, o uso seguro da tecnologia a partir da definição elaborada pelo Instituto Nacional de Tecnologias Educativas e de Formação de Professores, do governo espanhol: "el uso creativo, crítico y seguro de las TIC para alcanzar los objetivos relacionados con el trabajo, la empleabilidad, el aprendizaje, el tiempo libre, la inclusión y participación de la sociedad' (INTEF, 2017, p.12 apud Granados e Díaz, 2020), e coadunam com García; Torres e Rodríguez (2019) ao entendê-la como um conjunto de habilidades básicas, requisito para a aprendizagem ao longo da vida e melhora para inserção laboral. Engen (2019) considera que CD é um termo altamente político, por isso defende a necessidade de afastar-se de seu entendimento como conhecimentos e habilidades gerais sem referência a um contexto específico.

Embora Pettersson (2018) afirme que existem muitas pesquisas sobre CD e que parece não haver um consenso sobre o que realmente significa em contextos educacionais, o autor destaca a definição de Ferrari (2012):

The set of knowledge, skills, attitudes, abilities, strategies and awareness that are required when using ICT [information and communication technologies] and digital media to perform tasks; solve problems; communicate; manage information; collaborate; create and share content; and build knowledge effectively, efficiently, appropriately, critically, creatively, autonomously, flexibly, ethically, reflectively for work, leisure, participation, learning and socialising (Ferrari, 2012, p.30 apud Petterson, 2018, p. 1006).

Em uma perspectiva de segurança, Prendes; Porlán e Sánchez (2018) e Spante et al. (2018) concordam com o disposto nas Recomendações da Comissão Europeia (2006) que consta: "La competencia digital entraña el uso seguro y crítico de las tecnologías de la sociedad de la información (TSI) para el trabajo, el ocio y la comunicación"; e com a concepção de que são "valores, creencias, conocimientos, capacidades y actitudes para utilizar adecuadamente las tecnologías,[..] que permiten y posibilitan la búsqueda, el acceso, la organización y la utilización de la información con el fin de construir conocimiento" (GUTIÉRREZ, 2014, p. 54 apud PRENDES; PORLÁN; SÁNCHEZ, 2018, p.11).

Em seu artigo From digital literacy to digital competence: the teacher digital competency (TDC) framework, Falloon (2020) se apoia no entendimento de Janssen et al. (2013, p.480), que diz "digital competence should be understood as a pluralistic concept", o qual deve ser visto sob diversas perspectivas. Assim como Granados e Díaz (2020), o autor entende que a CD não se limita ao uso das TIC, mas se estende a conhecimentos e atitudes que que tangem eticidade e segurança, bem como a compreensão do papel das TIC na sociedade (Janssen et al. 2013, apud Fallon, 2020, p. 2451). Para finalizar o rol de contribuições dos autores do corpus analisado, cabe destacar as considerações de Gutiérrez e Tyner (2012, p.36), que dizem: "En la alfabetización de nuestra era, en este modelo de educación integral que proponemos para el nuevo milenio, atención especial merece lo que se ha dado en llamar competencia digital'. Segundo os autores, desde a última década do século XX começou-se a tratar a aprendizagem baseada em competências, o que resultou em políticas educacionais na Europa, como o Real Decreto 1513/2006 e, no contexto espanhol a Lei Orgânica de Educação, que passa a considerar como objetivo o desenvolvimento das competências básicas no ensino obrigatório, entre 
a quais está a CD, compreendida nestes documentos como: "consiste en disponer de habilidades para buscar, obtener, procesar y comunicar información, y para transformarla en conocimiento". Além disso, os autores ressalvam que são válidos os intentos das políticas públicas sobre a importância da CD como meio de participação cidadã, contudo, interpretações restritas ou distorcidas desta competência podem arruinar a proposta de alfabetização crítica proposta para a sociedade da informação.

Competência Digital Docente: Embora Engen (2019) considere que não há uma definição clara e precisa deste termo, a comunidade pesquisadora tem se dedicado a delimitar a CDD, a qual, parece denotar um conjunto mais complexo de habilidades e competências se comparada com as competências digitais necessárias para outras áreas da sociedade (PETTERSSON, 2017). Neste corpus, diversos autores convergiram em definições trazidas por outros importantes pesquisadores da área, a saber: "es la competencia del profesor/formador de profesores en el uso de las TIC en un contexto profesional con buen criterio pedagógico-didáctico y su conciencia de sus implicaciones para las estrategias de aprendizaje y la formación digital de los alumnos y estudiantes" (Krumsvik, 2011, p. 44 apud GRANADOS; DÍAZ, 2020; PRENDES; PORLÁN E SÁNCHEZ, 2018; PETTERSON, 2018; SPANTE et al., 2018). Destacam ainda, em palavras de Carrera e Coiduras (2012, p.12) que "incluye conocimientos, capacidades, actitudes y estrategias que el profesor debe ser capaz de activar, adoptar y gestionar en situaciones reales para facilitar el aprendizaje alcanzando mayores niveles de logro" (GRANADOS; DÍAZ, 2020; PRENDES; PORLÁN; SÁNCHEZ, 2018).

Os aspectos pedagógicos da competência digital e a forma como os docentes lidam com as TIC são aspectos que causam certa preocupação entre a comunidade acadêmica. Neste sentido, Prendes; Porlán; Sánchez (2018) destacam que é importante refletir sobre o papel do docente na atualidade, o qual foi radicalmente transformado pelas TIC, e que segundo Tejada (2009, p.11): "se tendrá que abogar por el dominio de nuevas competencias profesionales que garanticen tanto el saber, como el saber hacer, el saber estar y el saber hacer en y con TIC'. Outro fator a ser considerado é a realidade de cada local, uma vez que diferentes contextos apresentam diferentes necessidades, o que requer do docente um conhecimento dos aspectos sociais e culturais, concebido por Engen (2019) como a tradução do uso da tecnologia. Assim, ser competente digital no contexto educativo não é somente saber usar tecnologias ou integrá-las na prática pedagógica cotidiana; é algo muito mais amplo, porque requer matizar habilidades, saberes e atitudes em um movimento intelectual docente capaz de produzir e conectar conhecimentos em um desafio constante. Reddy; Sharma; Chaudhary (2020) destacam que as TIC tiveram muitos impactos positivos no campo da educação, sobretudo nas mudanças das práticas pedagógicas.

Buscando mostrar de forma visual como tais conceitos se representam na linguagem escrita, selecionou-se os três códigos no Atlas.ti (COMP, CD e CDD) e gerou-se uma nuvem de palavras com aquelas que apresentam maior frequência (Figura 6). Foram excluídas manualmente classes gramaticais como artigos, conjunções e preposições, visando deixar em evidência somente vocábulos com valor semântico para análise. 
Figura 6. Nuvem de palavras prevalecentes nas definições.

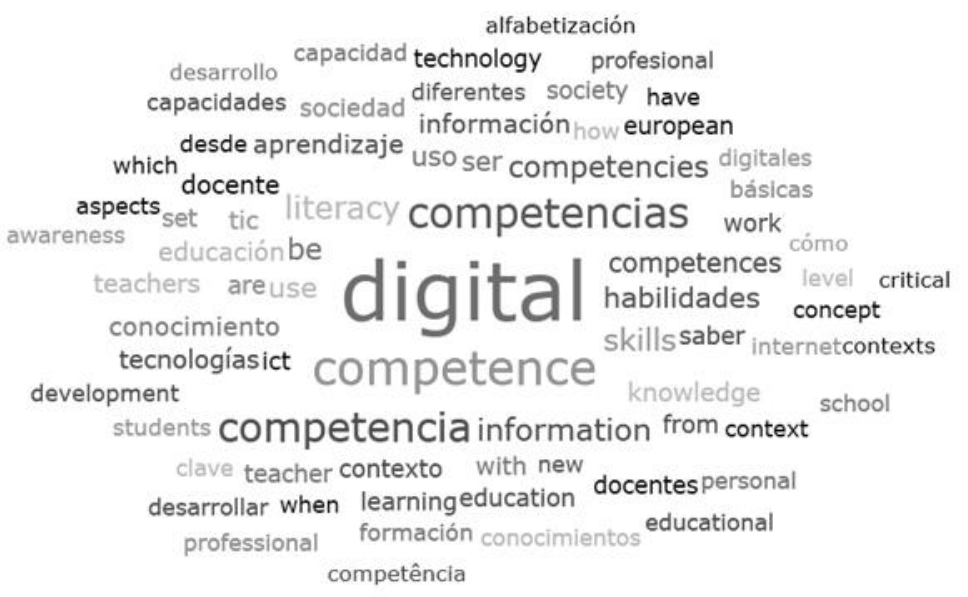

Fonte: Dados da pesquisa.

A Figura 6 revela o universo lexical incidente nas definições de COMP, CD e CDD no escopo desta pesquisa. Nota-se que se aproximam do centro importantes termos como habilidades, competências, informação, literacia, conhecimento, uso e tecnologias, o que denota uma tendência de uso destes atributos na elaboração de tais definições. Observa-se ainda, que este fenômeno ocorre de forma bastante simétrica nos dois idiomas do corpus analisado, o que permite inferir que estes são os termos prevalecentes na literatura internacional. Por fim, levando-se em conta aspectos semânticos emergentes na representação gráfica acima, entende-se que as competências e seus desdobramentos, como digital e docente, é um processo simbiótico entre humano e tecnologia, em uma relação que abrange esferas individuais, educacionais, políticas e sociais.

\section{DISCUSSÃo E CONTRIBUIÇÕES}

A riqueza de possibilidades do método $A C$, conjugada com análises qualitativas e quantitativas possibilitou identificar fenômenos específicos de padrões neste estudo. Exemplo disso, são as análises de ocorrências realizadas na categoria definição, o que permitiu identificar que, mesmo em referências cujos títulos constem CD ou CDD, não há em seu interior, nenhuma definição sobre elas, o que representa certa abstenção por parte dos autores. Se não tivessem sido aplicados diversos métodos de análise que abrangem dados de valores e dimensionamento de magnitudes sobre o corpus, este estudo seria mais superficial, imbricado somente na celeuma conceitual que já existe. Nesta senda, tratar a escassez ou ausência de definições, comprovadas por protocolos metodológicos, já representa uma contribuição na área. Ainda em estudo análogo, Silva e Behar (2019) destacam que embora tenha havido um aumento de publicações acerca de competências digitais nos últimos anos, ainda são poucas as experiências brasileiras sobre esta temática, assim, abordar este tema de interesse nacional, em língua portuguesa, é também uma contribuição ao público luso-falante.

Por outro lado, à luz dos autores abordados e pela função analítica de descrição das mensagens dos textos, foi possível observar que há nuances de entendimentos que tangem os termos COMP, CD e CDD, sendo algumas mais genéricas e outras cerceadas. Porém, como bem manifestam Gutiérrez; Tyner, (2012), muito se destaca na literatura as diferenças para defender as especificidades de cada termo, deixando-se de 
lado o fim comum, que é a formação integral do sujeito. Entende-se que o ideal para matizar as nuances existentes, seria uma visão holística e sistêmica sobre os temas em questão, uma vez que todos eles perpassam por questões que afetam a sociedade atual que é, cada vez mais, digital. Neste sentido, pressupõe-se que os matizes são os diversos termos emergentes na literatura, entre os quais identificou-se: competência audiovisual, competência midiática, literacia digital, letramento digital, competência em TICs, entre outros.

Buscando contribuir na composição de um referencial próprio sobre as três categorias de competências demandadas pela sociedade atual, elaborou-se conceitos próprios de forma sintética a partir das leituras das publicações analisadas e outras de igual importância. Sem refutar os conceitos já consolidados na literatura, nem tratar de questões epistemológicas, teóricas e políticas que possam estar de plano de fundo, as definições apresentadas a seguir são nada mais que entendimentos próprios que emergiram a partir deste estudo e que podem servir para referência e discussão de outros pesquisadores da área.

Quanto à Competência: Capacidade individual de mobilizar conhecimentos para aplicação em diferentes contextos. Requer do sujeito uma performance de reflexão e ação. Para Behar (2013, p. 21) "este termo é compreendido de acordo com o ponto de vista do indivíduo, ou seja, com a reunião ou conjunto de condições, recursos, elementos disponíveis aplicados em determinada situação". Cabe ressalvar que além das discussões conceituais, este termo passou a ser amplamente usado na forma plural na área educacional.

Quanto à Competência Digital: Capacidade de compreender, usar e integrar tecnologias digitais para uma participação cidadã, em uma dimensão que exacerba o uso instrumental e se expande para o ético, crítico, cultural e empoderado. Pressupõe o entendimento, tratamento e produção de informações, o uso de mídias e gêneros digitais, o confrontamento de verdades na rede e zela pela garantia de segurança de dados no espaço virtual. Krumsvik e Røkenes (2014) complementam que a CD requer do usuário uma grande variedade de habilidades complexas do tipo cognitivas, motoras, sociológicas e emocionais para o uso de ambientes digitais de maneira eficaz.

Quanto à Competência Digital Docente: Capacidade de compreender, usar e integrar tecnologias digitais para processos de ensino e aprendizagem em diferentes contextos. Exige flexibilidade, senso crítico e desejo de inovação por parte dos docentes. $O$ desenvolvimento destas competências em educadores é essencial porque eles são exemplos para a próxima geração e porque necessitam contribuir para a construção de um mundo dinâmico e moderno, globalizado e complexo (RUIZ CABEZAS et al., 2020).

Martino (2020, p.50) afirma que "dominar as tecnologias digitais, ter acesso não só à internet, mas também conhecer seus códigos e espaços, está vinculado às formações de poder contemporâneo". Assim, é impossível negar a tendência da digitalização da sociedade atual e a necessidade de desenvolver competências digitais para poder ser partícipe deste contexto, uma vez que através da integração das TDIC aplicadas na educação pode-se buscar a equidade de seu acesso e uso. Conforme ratifica Villa et al., (2019, p.4), "las TIC han cambiado en su totalidad la forma de gestionar negocios, servicios, la cultura y las relaciones humanas; sin embargo, aún su potencial no ha sido desarrollado del todo en muchos escenarios". Nesta senda, são de grande valia as iniciativas realizadas por organismos internacionais como Organização para a Cooperação e Desenvolvimento Econômico (2003), Organização das Nações Unidas 
para a Educação, a Ciência e a Cultura (2006), Conselho da União Europeia (2006), que podem replicar em políticas regionais e locais para a busca da cidadania digital da população.

Por fim, a partir da revisão de definições realizada nesta pesquisa, foi possível identificar algumas definições sobre competência, competência digital e competência digital docente, bem como elaborar uma definição própria com base em relevantes publicações. Ainda, percebeu-se que, mesmo em distintas formas de exprimir significados, há elementos predominantes e convergentes no entendimento dos autores, tais como habilidades, uso e literacia, o que, em uma análise léxico-estatística mais aprofundada, poderia resultar em um desdobramento deste estudo. Outra possibilidade de continuidade desta pesquisa é a análise dos elementos classificados na categoria "Outros" na etapa de pré-análise, que poderia resultar em levantamento e discussões sobre outros termos que se relacionam à competência digital.

Cabe destacar também que o software Atlas.ti mostrou-se adequado enquanto ferramenta para o método de AC. Suas funcionalidades qualificaram a pesquisa, sobretudo por favorecer o cruzamento de dados qualitativos e quantitativos, propiciando, assim, análises mais precisas, profundas e, ao mesmo tempo, otimizadas. Utilizá-lo no campo de pesquisas que envolvem análise de conteúdo de revisão de literatura na área da Educação é ainda incipiente, o que pode ser considerado também um diferencial deste estudo.

\section{CONSIDERAÇÕES FINAIS}

A pesquisa empreendida atingiu os objetivos delineados uma vez que, sem perder de vista suas limitações, efetivada em um corpus restrito, permitiu refletir e significar entendimentos sobre competência, competência digital e competência digital docente. Compreendeu-se o valor das TDIC como democratização da cultura e dos espaços de diferentes maneiras e a importância de saber produzir e encontrar informações de forma crítica e ética, em um uso superior ao instrumental, para participação cidadã na sociedade atual. Outrossim, ratificou a urgência de efetivação de agendas políticas que contemplem a fissura existente entre a necessidade dos cidadãos e a formação dos profissionais da educação no que tange as tecnologias digitais, cenário que se evidenciou ainda mais no contexto de pandemia vivenciado após o ano 2020.

Espera-se que, entre teoria e empiria, se possa avançar ainda mais em estudos sobre a temática abordada, tanto nas lacunas aqui deixadas, quanto em outros tantos aspectos ainda inexplorados por autores da área. Assim, deseja-se que este artigo possa contribuir na comunidade científica como documento de importância para aqueles que buscam entender o status quo das competências digitais no campo da Educação.

\section{REFERÊNCIAS}

BARDIN, L. Análise de Conteúdo. 3a impress ed. São Paulo: Edições 70, 2016.

BEHAR, P. A. Competências em Educação a Distância. Porto Alegre: Penso, 2013.

CARRERA FARRÁN, F. X.; COIDURAS RODRÍGUEZ, J. L. Identificación de la competencia digital del profesor universitario: un estudio exploratorio en el ámbito de las Ciencias Sociales. REDU. Revista de Docência Universitária, v. 10, n. 2, p. 273, 2 ago. 2012. 
DOANE, D. P.; SEWARD, L. E. Estatística Aplicada à Administração e à Economia. 4. ed. Porto Alegre: AMGH Editora Ltda., 2014.

ENGEN, B. K. Understanding social and cultural aspects of teachers' digital competencies. Comunicar, v. 27, n. 61, p. 9-19, 1 out. 2019.

ESPINOSA, M. P. P.; PORLÁN, I. G.; SÁNCHEZ, F. M. Competencia digital: una necesidad del profesorado universitario en el siglo XXI. Revista de Educación a Distancia (RED), n. 56, 30 jan. 2018.

EUROPEU, P.; CONSELHO DA UNIÃO EUROPEIA. Recomendação do Parlamento EuropeuBruxelas, 2006. Disponível em: https://eur-lex.europa.eu/legal-content/PT/TXT/PDF/?uri=CELEX:32006H0962\&from$=$ EN. Acesso em: 30 jun. 2020

FALLOON, G. From digital literacy to digital competence: the teacher digital competency (TDC) framework. Educational Technology Research and Development, v. 68, n. 5, p. 2449-2472, 29 out. 2020.

GARCÍA, A. M. R.; TORRES, J. M. T.; RODRÍGUEZ, J. S. Impacto de la productividad científica sobre competencia digital de los futuros docentes: aproximación bibliométrica en Scopus y Web of Science. Revista Complutense de Educación, v. 30, n. 2, p. 623-646, 9 abr. 2019.

GRANADOS, A. C.; DÍAZ, K. Y. A. Competencias digitales docentes: un acercamiento inicial. Revista Electrónica Calidad en la Educación Superior, v. 11, n. 1, p. 47-80, 2020.

GUTIÉRREZ, A.; TYNER, K. Media Education, Media Literacy and Digital Competence. Comunicar, v. 19, n. 38, p. 31-39, 1 mar. 2012.

JOHNSON, R. B.; ONWUEGBUZIE, A. J. Mixed Methods Research: A Research Paradigm Whose Time Has Come. Educational Researcher, v. 33, n. 7, p. 14-26, 2004.

KRUMSVIK, R. J.; RØKENES, F. M. Development of Student Teachers' Digital Competence in Teacher Education - A Literature Review. Nordic Journal of Digital Literacy, n. 4, p. 250-280, 2014.

LUCAS, M.; MOREIRA, A.; COSTA, N. Quadro europeu de referência para a competência digital: Subsídios para a sua compreensão e desenvolvimento. Observatório, v. 11, n. 4, p. 181-198, 2017.

MARTINO, L. M. S. Teoria das Mídias Digitais: linguagens, ambientes, redes. 2. ed. Petrópolis; RJ: Editora Vozes, 2020.

MATTOS, M. C. DE. Construção de um modelo de referência para aferição do nível de Competências Digitais de professores na Educação à Distância. [Tese.] Universidade Estadual do Norte Fluminense Darcy Ribeiro, 2019.

ORGANIZAÇÃO PARA A COOPERAÇÃO E DESENVOLVIMENTO ECONÔMICO. Measuring the Digital Transformation: A Roadmapd for the futureMeasuring the Digital Transformation. [s.l.] OECD, 11 mar. 2019.

PARK, H.; KIM, H. S.; PARK, H. W. A Scientometric Study of Digital Literacy, ICT Literacy, Information Literacy, and Media Literacy. Journal of Data and Information Science, p. 1-23, 24 jul. 2020.

PÉREZ, M. A.; DELGADO, Á. From Digital and Audiovisual Competence to Media Competence: Dimensions and indicators. Comunicar, v. 20, n. 39, p. 25-34, 1 out. 2012.

PETTERSSON, F. On the issues of digital competence in educational contexts - a review of literature. Education and Information Technologies, v. 23, n. 3, p. 1005-1021, 14 maio 2017.

REDDY, P.; SHARMA, B.; CHAUDHARY, K. Digital literacy: A review of literature. International Journal of Technoethics, v. 11, n. 2, p. 65-94, 2020.

RUIZ CABEZAS, A. et al. Formación del Profesorado Universitario en la Competencia Digital. Pixel-Bit, Revista de Medios y Educación, v. 58, n. 58, p. 181-215, 2020.

SÁ, P.; PAIXÃO, F. Contributos para a clarificação do conceito de competência numa perspetiva integrada e sistémica. Revista Portuguesa de Educação, v. 26, n. 1, p. 87, 2013.

SILVA, B. Aprendizagem na cibercultura: Um novo olhar sobre as Tecnologias de Informação e Comunicação Digital no contexto educativo ubíquo. Interfaces Científicas - Educação, v. 6, n. 3, p. 17, 2018. 
SILVA, K. K. A. DA; BEHAR, P. A. Competências Digitais na Educação: uma discussão acerca do conceito. Educação em Revista, v. 35, 2019.

SILVA JUNIOR, L. A.; LEÃO, M. B. C. O software Atlas.ti como recurso para a análise de conteúdo: analisando a robótica no Ensino de Ciências em teses brasileiras. Ciência \& Educação (Bauru), v. 24, n. 3, p. 715-728, set. 2018.

SPANTE, M. Hashemi, S. S.; Lundin, M.; Algers, A.Wang, S. Digital competence and digital literacy in higher education research: Systematic review of concept use. Cogent Education, v. 5, n. 1, p. 1519143, 1 jan. 2018.

STORDY, P. H. Taxonomy of Literacies Introduction. Journal of Documentation, v. 17, n. 3, p. 456-476, 2015.

TEJADA, J. Competências docentes. Profesorado, v. 13, n. 2, 2009.

UNIDAS, O. DAS N. Marco de competencias de los docentes en materia de TIC UNESCO. [s...] Library, UNESCO Digital, 2019.

VILLA, S. V. et al. Competencias Docentes y Transformaciones en la Educación en la Era Digital. Formación universitária, v. 12, n. 6, p. 3-14, dez. 2019.

YIN, R. K. Pesquisa qualitativa do início ao fim. Porto Alegre: Penso, 2016.

ZAVALA, D.; MUÑOZ, K.; LOZANO, E. Un enfoque de las competencias digitales de los docentes. Revista Publicando, v. 3, n. 9, p. 330-340, 30 jan. 2017.

Data da submissão: $31 / 03 / 2020$

Data da aprovação: 31/07/2021 